\title{
A case based study of design strategies to explore the notion of age-friendly co-housing community
}

\author{
Jingyi $\mathrm{Ye}^{1}$, Zhengwang $\mathrm{Wu}^{1 *}$ \\ 1,*'School of Architecture, Huaqiao University, Xiamen, Fujian Province, 361021, China
}

\begin{abstract}
Globally, the proportion of the older people population is growing and this will continue to rise. 1 out of every 4 people in cities will be an older person by $2050^{[1]}$ (World Health Organization, 2007). An agefriendly co-housing is an sustainable community, considering long-term interests, age-friendly co-housing can not only reduce social welfare expenditure, but also give full play of older people's positive impact in society. Age-friendly co-housing requires more theoretical support and practice. The case analysis of two cohousing projects for older people are from the United Kingdom (London) and the United States (Oakland). The article analyzes and evaluates the case studies by using the WHO domains (see Table 1) and then concludes the design strategies from three aspects- outer space, communal space, and private residential space. This essay endeavored to explore the potential of age-friendly collective housing for older people, that is to say, connect age-friendly concept which is a hot issue today with co-housing model to solve the current ageism and population aging problems. A single design method cannot satisfy older people's psychic needs, therefore, this article provides age-friendly co-housing with authoritative scientific theoretical background of interdisciplinary as the data collected from diverse fields as architecture, ecology, psychiatry, ergonomics and human sociology.
\end{abstract}

\section{Introduction}

In the current age of population aging, the World Health Organization has proposed the concept of age-friendly cities and defining it as an ideal city model for older adults to age actively (WHO, 2007). According to active aging strategy which is to build age-friendly places and inclusive neighborhoods, age-friendly cities are an effective way of planning for the upcoming demographic change. It is proposed that in the process of urban planning and design, it should be able to promote people's active participation on the basis of independent living, and the people of all ages should have a good quality and decent life.

Meanwhile, co-housing is designed to support and enable a healthy active life for people as they get older and has become an attractive way that some older people are looking to live in later life. In the design process of agefriendly co-housing, it should have been fully considered to provide the corresponding facilities and services for the older people, to enable the older people to live healthily and safely. Residents have no obstacles in on-site home care and truly realize living in a lifetime dwelling.

Helping aging population to settle into affordable, accessible and stable housing is a major challenge for modern society, especially during periods of rising housing costs. New building environmental models are needed to reduce social isolation, and the cost of care. On the other hand, Most people would love to be in comfortable and independent houses when they get older, which allows them to stay in touch with family and friends.

Table 1. The eight domains of an age-friendly city topic areas (World Health Organization, 2007)

\begin{tabular}{|c|c|}
\hline No. & Item \\
\hline 1 & Outdoor spaces and buildings \\
\hline 2 & Transportation \\
\hline 3 & Housing \\
\hline 4 & Social participation \\
\hline 5 & Respect and social inclusion \\
\hline 6 & Civic participation and employment \\
\hline 7 & Communication and information \\
\hline 8 & Community support and health services \\
\hline
\end{tabular}

An age-friendly co-housing is a collective housing which allows people aging well and actively, to gain

\footnotetext{
* Corresponding author: wuzhengwang@126.com
} 
privacy, independence, safety at the same time and helps people to reduce loneliness, isolation, to have active social interaction, convenient health care and good relationships with their neighbors when they grow older.

Even though co-housing can make communities more age-friendly, the link between older people's co-housing and the concept of age-friendly has not been explored from an architectural perspective. It's necessary to fill this gap in knowledge. Besides, little is known about architectural and spatial models in older people's cohousing, and the spatial planning and design strategies for independent age-friendly co-housing communities. This paper wants to find out architectural and spatial typologies in age-friendly co-housing, assesses case studies, presents spatial planning and design strategies for independent agefriendly communities.

This study has certain practical significance and application value. To capture the successful age-friendly co-housing cases and conclude the design strategies has a significant meaning on providing older people with interactions and participating, increasing the intimacy of the residents, creating a sense of happiness in the living space. For the first time, this study combines the agefriendly model with the co-housing model from an architectural perspective, and sublimates the age-friendly co-housing concept from the single senior co-housing domain, and proposes corresponding design methods and strategies. However, it still doesn't solve the difficulties that they would be encountered in the course of practice, such as budget, people's ideology problems, negotiation and communication problems when processing. Drawing the connections between age-friendly as a concept and cohousing as an application is novel and fairly original, but the choice of the 2 case studies seems to have limited the opportunities to explore this fully. This is still a frontier field- how to make a good theoretical utopia into a livelihood project is one of the key issues for the nextstage theoretical study.

\section{Case Studies 1- New Ground Co- housing}

The Older Women's Co-housing (known as OWCH) group was set up in 1998 following an event on co-housing hosted by the National Council for Voluntary Organizations, and then it developed first British older women's co-housing community - New Ground Cohousing in High Barnet, North London, and it was opened in the end November 2016. New Ground Co-housing is neoteric, purpose-built flats, and it includes 25 one to three-bedroom apartments, 17 flats of which are rented homes operated by Housing for Women and 8 are owner occupied private housing. In fact, the tenants are mostly between the ages of 54 and 90, with an average age of 73 . [2] In addition, they come from different professional backgrounds. 20 of the twenty-two residents are English whites, 2 of whom are Iranian refugees. The residents are mingled in career, wealth and race, they are therefore warm and colorful.

New Ground Co-housing is designed for comfort aging and increased sensitivity by architect Pollard
Thomas Edwards (PTE) and developed by partner Housing for Women, Hanover Housing Association and Tudor Trust Funder. It has received many accolades and awards for its very pleasing, age-friendly architecture and plenty of light, private space, storage space, and shared facilities in the community, among which include the European Collaborative Housing Award, etc and these are well deserved.

\subsection{The Background of New Ground Co-housing}

A group of women in their fifties designed their own communities. Instead of living alone, they choose to live with helpful friendly neighbors, and they share co-values and do things together. The aim of the $\mathrm{OWCH}$ is to promote neighborliness, combat isolation and offer mutual support, encourage residents to be involved with their local community. This aim has successfully achieved from the latest report that the older women has not only gained mental support from one another facing the lockdown situation, but also managed to thrive and look out for one another physically in this COVID-19 disaster. To keep morale high, they are permitted to join exercise classes in a small group of less than 6 people. The communal space like hallways are sanitized in turns. Daily maintenance is continue to conduct as usual ${ }^{[3]}$.

New Ground Co-housing has an resident election association to make decisions through a monthly meeting. Nominees for OWCH need to go through the selection process and be accepted by the management group. They regularly invite a group of non-resident members to participate in the community event. As it shown in Fig. 3, the co-houser representative is working with local government staff on the future plan of their dream house. This helps to solve the problem of co-housing being misunderstood in the development process and making it better spread to other countries and places and to improve the integration of the co-housing community with surrounding communities ${ }^{[4]}$.

\subsection{The Design Strategies of New Ground Co- housing}

Outer Space- The project consists of two-story houses along the street and three-storey houses that surround the courtyard with different roof forms. The five buildings inside the courtyard form a modern style from the threeslope roof, while the five buildings along the street use a low-sloping pyramid-shaped roof to coordinate with the Georgian and Victorian buildings. The use of lightcoloured brick walls transitions the facade of the surrounding red and white walls to create a coordinated neighborhood atmosphere.

Viewing from outside, the six blocks seem to be one, although the whole facade is built in new brickwork with subtly different facade rhythm. There are 2 shared front entrances, one leads to the parking court, the other next to the communal house is a walking entrance. Instead of entering a hall or porch, you are walmly welcome to enter a communal house. Continue to go inside, you will see a large interior garden which ends with a glazed 
retractable back wall.

Communal space - Common areas including a parking court, a shared lounge, a deluxe guest room, a communal laundry with a laundry garden, an age-friendly elevator for disabled people, and a shared common house with a meeting room, a communal kitchen and a big dining hall filled with comfortable furniture, that the residents manage by themselves, see Fig. 1 and Fig. 6. They also share 2 very large rear gardens with allotments.

Communal house is the core of the plan, while other communal facilities are dotted throughout the building. The communal gathering meal is held once a week in normal time, but since the COVID-19 lockdown, this weekly routine has to be canceled.

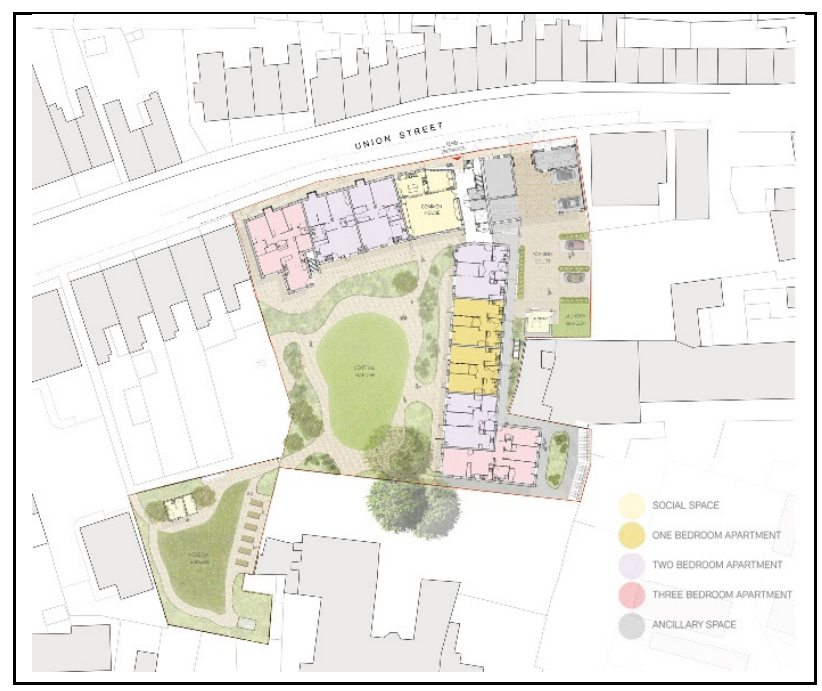

Fig. 1. New ground co-housing ground floor plan (NaCSBA)

The most important principle for co-housing is about mutual support. Everyone should pay efforts to a series of teamwork, for example, making development plans, cleaning, gardening, maintenance, taking prescriptions for others, discussing future plan and finance issues, joining weekly meal and social events, like it is shown in Fig. 2/3.

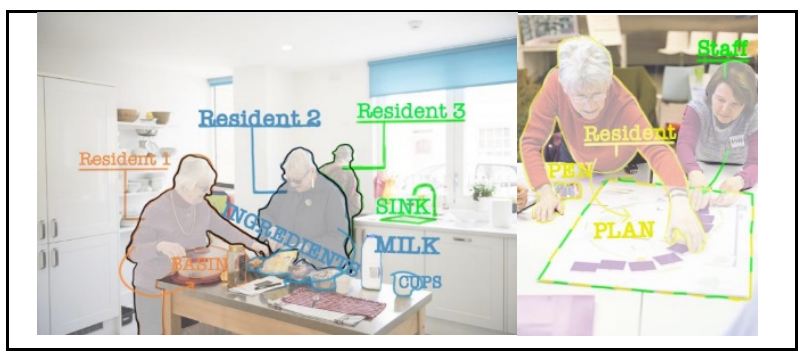

Fig. 2/3. Diagram showing the picture of the communal house with an overlay of annotated items and arrangement. Older residents cooking together and manage the future of their dream house (Author owns)

Private residential space - This pioneering cohousing scheme creates 25 customized homes, each of which has its own balcony or patio, most of the residents have large balconies that can accommodate loungers or dining tables. Most of the windowsills face the inner courtyard and overlook the shared internal garden nicely and warmly, the essence is to enhance the interaction of the neighborhood.

The apartment itself is a bright, airy and spacious space, there are one, two and three bedroom flats. In the interiors of the house, large windows, generous balconies and patios link the women residents to the outside world so as to enjoy the gentle daylight or just ignite a cigarette and look over the garden. Kitchen windows offer a glimpse into the house for a casual wave as one passes. The building environment is serene and has become lifetime home to those who live here.

\subsection{How does it achieve the goal of age-friendly?}

In a cautious balance between shared and personal space, individuals and groups, the co-housing usually give a good performance to protecting privacy, and this is the foothold of New Ground Co-housing's main goal. The co-housing members can meet each other casually while it is possible to retreat into their own private space easily as well. The design of 'New Ground Co-housing' achieves important objectives set by the $\mathrm{OWCH}$ group that internal circulation and communal spaces should facilitate social interaction. The apartment has a very private secluded atmosphere, space like bedroom, study offers a break for the residents, but the kitchen, balcony and other space facing the garden connect the common areas.

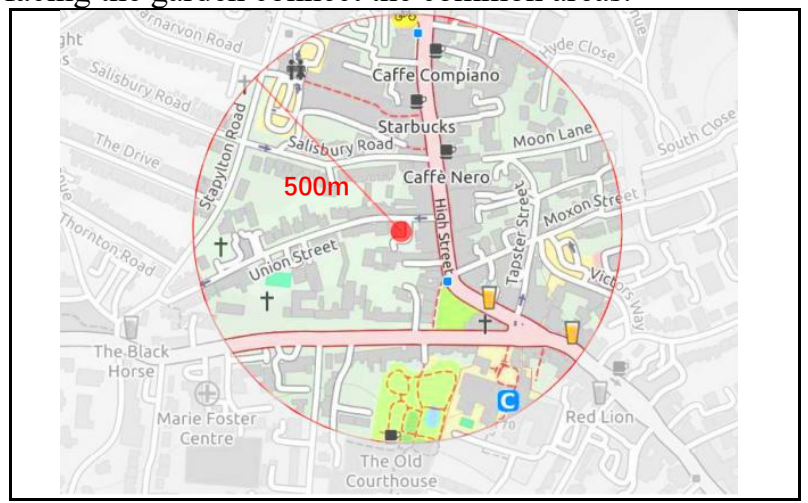

Fig. 4. New ground co-housing public service 500m walking circle diagram (Author owns)

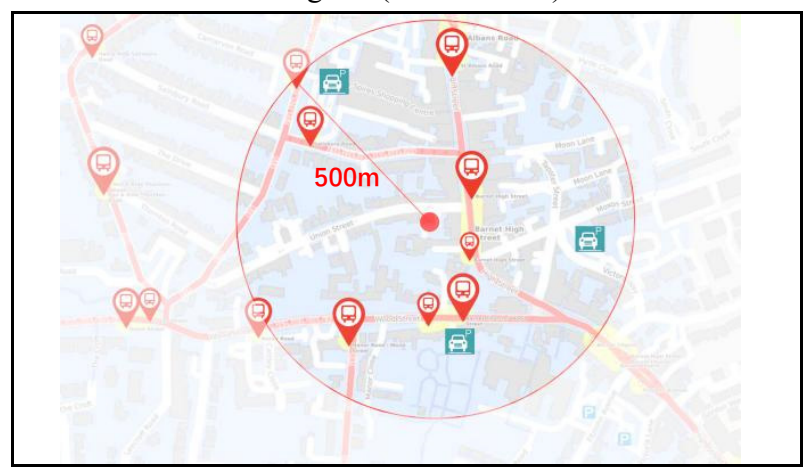

Fig. 5. New ground co-housing transportation 500m walking circle diagram (Author owns)

In the design phase, the design team has simulated a variety of possibilities to set the tone for a friendly neighborhood, such as how healthy residents look after sick residents, weekly movie nights, yoga classes, sketch interest groups, book a journey easily through email, and some members can spend the summer together outside, 
and these are constantly being implemented and developed.

As it vividly shown in Fig. 4 and Fig. 5, the co-housing is in good location. The speed of people's walk is from $1.1 \mathrm{~m} / \mathrm{s}-1.5 \mathrm{~m} / \mathrm{s}$, then the 500 -meter service circle means it will take the residents less than 8 minutes to get to the nearby 8 bus stations. There are lots of restaurants, cafes in the neighborhood, which are in an acceptable distance from New Ground Co-housing. A local church, a clinic and two parks are also within appropriate walking distance. The site location is close to the public transportation, and most residents of the community are happy to use sustainable ways to go outside, such as walking, cycling, buses, or shared cars.

\section{Case Studies 2- Swan's Market Co- housing}

Swan's Market Co-housing, which also called Old Oakland Co-Housing is located in the heart of Oakland, USA. This historic landmark has won 2001 Rudy Bruner Award Silver Medal for this innovative comprehensive historical conservation project that restores an abandoned old market building offering affordable rental apartments, cafes, Japanese restaurants, flower shops, retail stores, restaurants, professional offices, public courtyard, art gallery and clothing stores ${ }^{[5]}$. The whole structure were adapted to the original market hall. It is the 50th common housing community in North America and was designed and built by Katherine McCamant from Co-Housing Solutions who is an international expert in co-housing.

Organizing the development process, working with potential collaborators and delivering pre-sale units came to Katie. She described co-housing's founders are inspired by the growing popularity of shared families and collaborative community campaigns, where several unconnected people share a traditional home. At the same time, co-housing is unique that each family has independent residence and can actively choose the extent to which they want to participate in community activities ${ }^{[6]}$.

Swan's Market Co-housing was built in March 2000 and consisted of 18 market-priced apartment units, four of which are for AIDS patients, and a central common house in the middle of the layout. The residents of Swan's Market Co-housing are mainly adults and their children. The older people have abundant skills and interests and can share many life experiences. Both the young and the old are equally important to communities, social networks and environmental sustainability.

\subsection{The History of Swan's Market Co-housing}

Oakland Free Market first established near the site in 1890. Afterwards, Housewives Market opened on the spot in 1907. The Swan's market was built by Jacob Pantosky in phases from 1917 to 1927 , when it was sold to Sherwood Swan and Company. This landmark was used most of the time as a department store and food market.

In the early 20th century, fourteen blocks from the City Hall to the waterfront on Washington Street were the bustling commercial center of downtown Oakland,
California, near Old Oakland. Swan's Market was located between 9th and 10th Streets in Washington Street, and then gradually integrated and replaced surrounding buildings and included the entire city block in the end ${ }^{[5]}$.

In the 1940s, when the population of Oakland flooded into the south, they moved to work at the shipyard, and the Swan's market has become an informal living room for new immigrants. Later on, the Swan's market closed in 1984, which was then abandoned after the 1989 Loma Prieta earthquake.

In December 1994, the Common Housing Corporation advertised a common housing development project for people who are interested in living in the Swan's market. 15 people attended and participated in the discussion. Today's Old Oakland Co-Housing was completed in $2000^{[5]}$

\subsection{The Design Strategies of Swan's Market Co- housing}

Outer Space- The structure of the Swan's Market buildings used to be brick and steel. During the renovation process, the steel beams were exposed, the brick and tile exterior walls were preserved, and the original glazing wall was used for the facade restoration.

"Swan's Way" is home to a large number of fruit trees, vegetables and cleverly designed courtyard gardens. Furthermore, commercial users and apartment residents share parking lot on the ground floor.

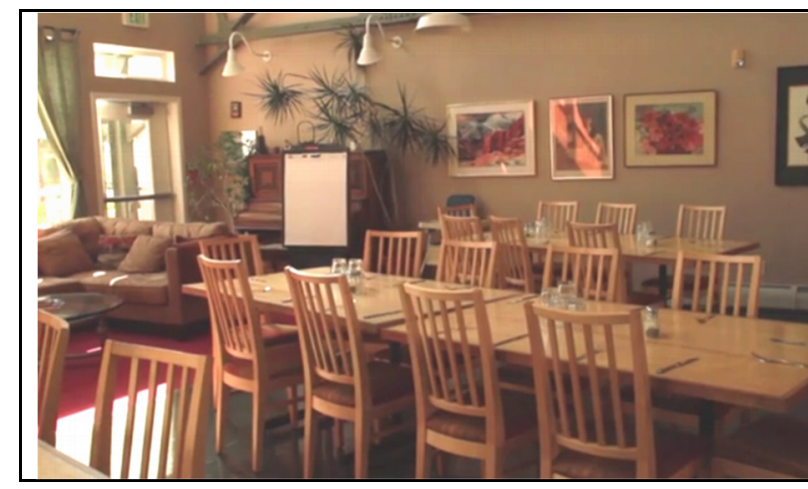

Fig. 6. Co-housing communal house interior (Respectful Revolution, 2013)

Communal space - All the traditional components of collective housing are active here, including community meals three times a week in the communal house, see Fig. 6, monthly official parties and mutual help among the neighbors. Community involvement is extremely high here, and residents can share food, tools, time, friendships, resources and skills through communal gardens which have an orchard and vegetable beds, see Fig. 7. The communal gardens have grown a lot of things they can cook and eat. Cars are kept out of the way in car parks. 


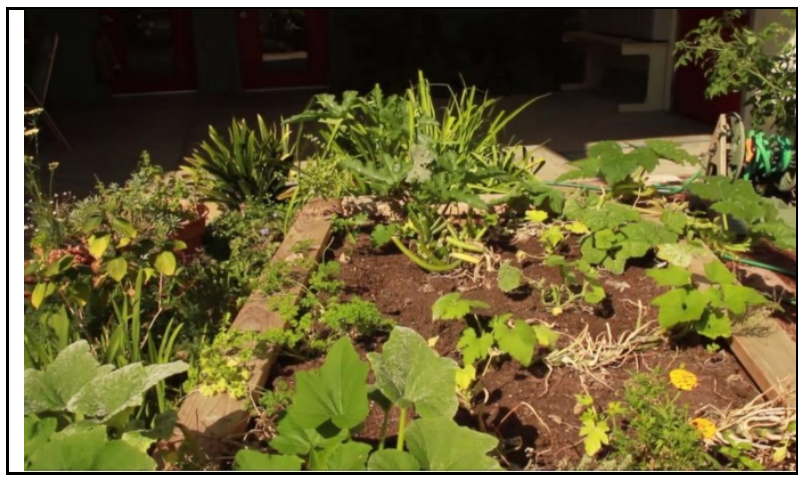

Fig. 7. Allotments in communal garden (Respectful Revolution, 2013)

Community facilities include a 3,500-square-foot common house served as many purposes in the majorities of co-housing communities, with large kitchen and dining area, children's playroom, exercise room, laundry room, workshop, community garden, guest room, large dining room and entertaining courtyard. Residents often eat, play, have meeting, and do yoga here. The community eats together a couple of nights a week in the common house, as one of the residents Neil Planchon says "Common dinners are the glue that keep us together". Residents are committed to participating in cooking rotations and other tasks needed to support community maintenance and selfmanagement. Many older people are wary of shared spaces, but well-designed elements such as vegetable gardens can reduce the cost of living and social isolation (see Fig. 7).

The first floor public walkway space is decorated with bonsai from house to house and becomes a public green walkway. Along the walkway, several little open areas which have been put outdoor tables and seats are a community gathering spot shown in Fig. 8. below. Residents would come out and meet, and may have unplanned pet walks or just take out newspaper and enjoy a cup of tea with whoever happens to sit here.

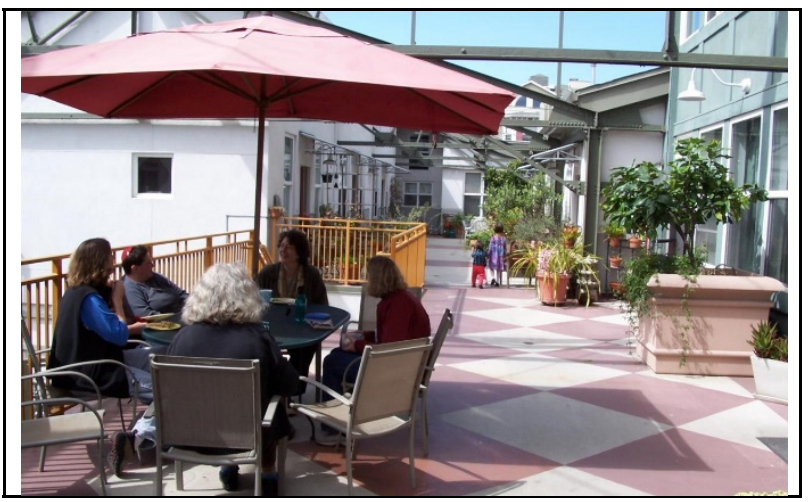

Fig. 8. People chat on co-housing exterior seats and potted plants in the walkway (Respectful Revolution, 2013)

Private residential space - The project's 18 homes are single-story units on the first floor of Swan's Market. Residents can enter the community from both the west side of Swan's Way or the south side of Swan's Court, walking pass the shared staircase next to the communal garden to co-housing community on the first floor. The roof of several households on the west side are equipped with solar panels to save energy. The three southwestern units have balconies facing the Swan's Way, and there are large windows facing the $10^{\text {th }}$ Street and Swan's Walk for the northern units, which were preserved in the original form of the market before the renovation, while windows of the five households on the southeast only open to the inner Swan's Walk inside the community. All units have their own skylights to ensure adequate daylighting.

\subsection{How does it achieve the goal of age-friendly?}

For the best aging experience, residents need welldesigned, well-located homes which are close to shops, public services and other facilities, at the same time, it's really nice to have support from friends and social networks.

Located in the heart of bustling Old Oakland, Swan's Market Co-housing is just 2 blocks from the BART (Bay Area Rapid Transit) station and 15 minutes from downtown Oakland to downtown San Francisco or Berkeley city center by BART, residents can enjoy almost all services within a few blocks, including the Farmers Market on crossing of Washington Street and 9th Street.

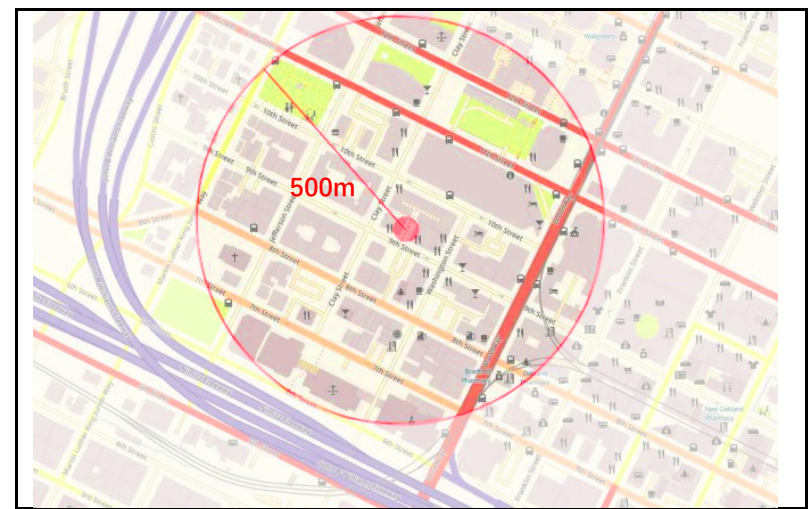

Fig. 9. Swan's Market co-housing public service 500m walking circle diagram (author owns)

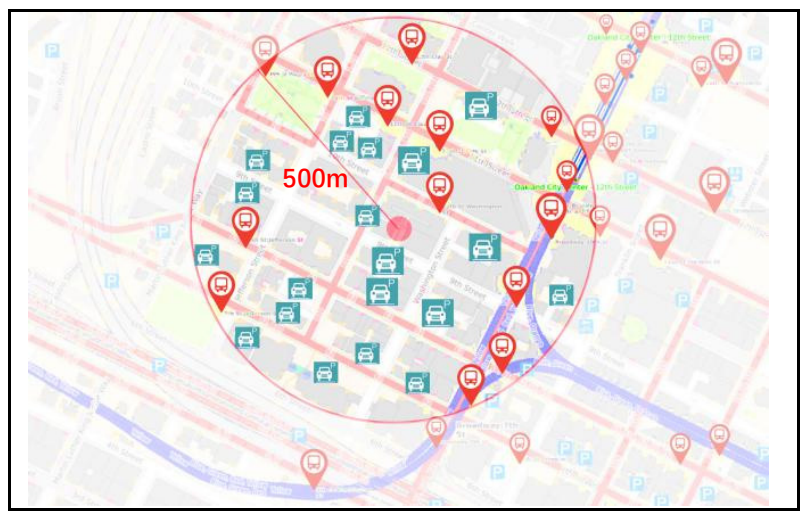

Fig. 10. Swan's Market co-housing transportation 500m walking circle diagram (author owns)

As we can see in Fig. 9-10, the cohabiting residents have the incredible convenience of downtown life- the "walking distance" of almost everything (restaurants, parks, churches, museums, theaters, entertainment, workplaces, galleries, shopping, Chinatown), extensive public transport, and vibrant city life nearby. It takes less than 8 minutes to get to the nearby 14 bus stations, not to 
mention there are 20 parking lot in the neighborhood, which is an age-friendly walking distance to get to anywhere either taking your own car or using the public transportation. Therefore, the life here is rather cozy and convenient for older people, which we can say it represents a good example of age-friendly transportation domain.

The project is a mix of different age groups. The project does not isolate older people from young people, allowing older people to enjoy the same treatment while living in the family. Families moved in because parents thought that sharing parenting would be good for their children and children would gain knowledge from interacting with older residents. Residents say that in the Swan's Market co-housing, children have better social skills, and the older residents without children and grandchildren of their own get to enjoy a sense of multigenerational family.

When older people meet children in street or children's museum or even children's playgrounds in shared units, older people can impart their knowledge and experience to children while at the same time enjoying the happiness of being associated with children. Children run back and forth, enjoying a communal playground while the older people may be inconvenient to move, however, with the help of children's lively and innocent characteristics, their sight is attracted and moved with the movement of children, which is also a great comfort to the older people. This will keep the older people involved, active and happy.

There is evidence that people who volunteer in their later years have increased their sense of presence, happiness and social relationships. Swan's Market Cohousing can do voluntary work in the co-housing association or being the staff members with paid employment.

\section{Discussion}

In the case studies of New Ground Co-housing and Swan's Market Co-housing, it's been found that both of these communities meet with age-friendly 8 domains. Both cases have an introverted layout that protects the privacy of the community. Although the New Ground Co-housing is in the suburbs of London, life is still convenient. Located in the heart of Oakland's city center, Swan's Market Co-housing offers everything the residents need within a convenient walking distance. These two projects provide affordable housing that allows residents of all income levels to enjoy low-cost, high-quality living. New Ground Co-housing has accepted two Iranian refugees, and Swan's Market Co-housing has accepted four AIDS patients, residents come from a variety of backgrounds and cultures, and this shows the respect for humanity. Swan's Market Co-housing often interacts with the surroundings, including a variety of activities with surrounding galleries, work spaces, and Children's Art Museum. And they regularly organizes visiting tours for people who are interested in exploring a more communal way of life. New ground Co-housing, on the contrary, in order to ensure the privacy of residents and the normal life not to be disturbed, they do not carry out activities towards outside community.

From the perspective of common features, both cases offer rental apartments as well as owner occupied houses, common facilities, common houses, common land, regular meetings, and shared meals. New Ground Co-housing is a pure residential project while Swan's Market Co-housing is part of a mixed-use building complex with retail, office space and multiple kinds of housing.

As far as I am concerned, older people's co-housing doesn't equal to the concept of age-friendly co-housing. An age-friendly co-housing doesn't have to be an older people's co-housing, it can be inter-generational community with children, teenagers, young people, middle-aged people, and older people. Take Moora Morra Co-housing Community in Australia as an example, Moora Moora is a co-housing community in Mountain Toolebewong to the southeast corner of Australia. It is made up of approximately 50 adults, aged from 30 s to 90 s, and 20 children. It is suitable for families with young children, parents and older people where every member lives together in a harmony. Common meals, amusement facilities and community-organized activities have had a huge impact on the quality of life for all members of the community. This is an age-friendly co-housing, but not an older people's co-housing. That is to say, age-friendly cohousing should meet the requirements of older people's co-housing, while they can be multi-generational or just older people's community depending on the residents' common will.

The age-friendly co-housing concept works for people of all ages and stages of life. Plus, the Swan's market cohousing is also family based. From this perspective, the WHO sectors are better realized in this kind of agefriendly co-housing than specific age co-housing.

Co-housing community is also suitable for those who choose to adapt to live alone in older age, where they can share their strengths and resources with other neighbors, and contribute to sustained social interaction and social participation ${ }^{[7]}$. Co-housing can ensure the communities to be more age-friendly, no matter it is an older people's cohousing or an age-friendly co-housing.

Accessible and affordable health care services can be reached within 10 minutes in both community. On the one hand, the nearest one for Swan's Market Co-housing is Third Street Outpatient Clinic which is 10-minute walking distance, on the other hand, it takes 6 minutes to walk to the nearest Jesus Hospital Charity from New Ground Cohousing.

Visualized signage helps older people find services more easily and enhances communication, especially with identifying landmarks. For example, the most representative corner with a huge striking billboard of Swan's Market.

\section{Conclusion}

The essay focuses on setting up a new model to reduce social isolation, cost of care for older people, proposing corresponding design methods and strategies, combing the co-housing research of shared concepts with the agefriendly architectural and spatial models in older people's 
co-housing, finding out architectural and spatial typologies in the spatial planning and design strategies for age-friendly co-housing communities. This replicable model allows anyone who wants to live this way to imitate.

An age-friendly co-housing is a sustainable community, considering long-term interests, age-friendly co-housing can not only reduce social welfare expenditure, but also give full play of older people's positive impact in society.

An age-friendly co-housing is a community where residents help each other, and the community provides a better mechanism for aging. An age-friendly co-housing is a co-housing which allows people aging well and actively, to gain privacy, independence, safety, meanwhile, helps people to reduce loneliness, isolation, to have active social interaction, convenient health care and good relationships with their neighbors when they grow older.

An age-friendly co-housing is a healthy and sustainable multi-generational, inclusive community. An age-friendly co-housing should consider and meet with the requests of age-friendly eight domains. Based on its various advantages and benefits, co-housing can contribute to make an age-friendly city in many ways include:

A. Health Support

Health care centers should be close to the community, placing the older people on spot, reducing the cost of medical nursing care. Reducing the number of older people going to nursing homes or health care centers, and provide the possibility of home-based care. Age-friendly co-housing would be fully considered to provide the corresponding facilities and services for the older people, to enable the older people to live healthily and safely. Residents have no obstacles in on-site home care and truly realize living in a lifetime housing.

B. Social Respect and Social Participation

Reducing the sense of independence and isolation of older people by establishing social connections and communication. It responds to the age-friendly domainSocial Respect and Social Participation.

C. Communication and Information

Enhancing opportunities for the exchange of knowledge and skills through common activities, increasing the possibility of inter-generational communication and skill sharing, providing technical support services for older people, such as the support of necessary communication technology in daily life, entertainment programs, and ample social occasion suitable for older people.

D. Housing

Reducing the housing quantity of a single person, reduce the cost of living, and customize the supply of housing according to the needs of the residents, ensuring affordable housing and support for the older people, offering accessibility and plenty of space for older people to live independently comfortably and safely at home.

E. Social participation

The design process of age-friendly co-housing is fully involved by residents. Letting the older people participate more actively in the community life, and encouraging spontaneous interaction, spontaneous management and spontaneous maintenance in the neighborhood.
In the design process of architectural space, we should promote an age-friendly and comfortable living of all ages, and solve the problems of neighborhood isolation and lack of communication brought by the design of modern urban community.

In the end, I believe that age-friendly co-housing model has been successful in its approach to the population aging context, this study did not end here, for the increasing aging population and all the superiority of age-friendly co-housing communities, this topic will continue, be better interpreted and developed in the future.

\section{Acknowledgments}

This essay is supported by the Scientific Research Funds of Huaqiao University, 605-50X19022.

\section{References}

1. WHO, Global Age-friendly Cities: A Guide (2007)

2. OWCH, http://www.owch.org.uk/ (2019)

3. N.Jones, TBS, Life under lockdown at cohousing flats for older women, https://www.barnetsociety.org.uk/component/k2/lifeunder-lockdown-at-cohousing-flats-for-older-women (2020)

4. F.Chiodelli, V.Baglione. U.R., Living together privately: for a cautious reading of cohousing, 7, 20 34 (2014)

5. Pyatok Architects, 2001 Rudy Bruner Award Silver Medal Winner, Swan's Marketplace Oakland, California. In Committee RBAA (ed.) (2001)

6. K.McCamant, Durrett C. Co-housing: A Contemporary Approach to Housing Ourselves. 2nd ed., USA: Better World Books (1994)

7. M.Brenton, The Nesta Foundation, Potential benifits of Co-housing for older people (2010) 